\title{
Estudo da utilização do PVC como constituinte de concreto reciclado
}

Study of the use of pvc as a refilled concrete constituinte

\author{
Alexandro Batalha Batista ${ }^{\dagger}$, Leandro Rosa Januário dos Santos ${ }^{\dagger}$, Marcela Saboya Ribeiro ${ }^{\dagger}$, Gustavo \\ José da Costa Gomes**
}

Como citar esse artigo. Batista, $\mathrm{ABB}$; dos Santos, LRJ; Ribeiro, MS; Gomes, GJC. Estudo da utilização do PVC como constituintedeconcretoreciclado. Revista Teccen. 2018 Jan/Jun.; 11 (1): 39-46.

\begin{abstract}
Resumo
O emprego de teores de cal hidratada em materiais cimentícios promove alterações demandadas quanto ao seu uso em ambientes críticos. As adições dispostas visam intervir no consumo de hidróxido de cálcio oriundo da hidratação, que ocasiona a diminuição deste composto, levando a um estado superior de facilidade de entrada de íons corrosivos, promovendo desgaste da armadura, uma vez o $\mathrm{pH}$ diminuído devido a isto. Foram utilizados para análise, corpos-deprova com aglomerantes com teores de $100 \%$ de cimento Portland, outros com $20 \%$ de adição de cal hidratada e os demais com $50 \%$ de adição do referido composto. Todos os teores possuem corpos-de-prova variando com o fator água/ aglomerantes em 0,$4 ; 0,5$ e 0,6, com o intuito de investigar a contribuição da adição da cal hidratada na permeabilidade do concreto elaborado, em teste de permeabilidade e também seu aporte quanto às características físicas dos corposde-prova em ensaio de compressão mecânica. Observou-se que as massas elaboradas com a cal hidratada possuíam um menor índice de vazios, oriundo da evaporação da água, influenciando na permeabilidade da pasta, que contribui significativamente na permissividade de agentes agressivos.

Palavras-Chave: Cal, Concreto, Permeabilidade.
\end{abstract}

\begin{abstract}
The use of hydrated lime contents in cementitious materials promotes changes in its use in critical environments. The additions are intended to interfere in the consumption of calcium hydroxide from the hydration, which causes the reduction of this compound, leading to a superior state of ease of entry of corrosive ions, promoting wear of the reinforcement once the $\mathrm{pH}$ is decreased due to this. Batch test specimens with $100 \%$ Portland cement, $20 \%$ hydrated lime addition, and 50 $\%$ addition of said compound were used for the analysis. All contents have specimens varying with the water / binder factor by $0.4 ; 0.5$ and 0.6 , in order to investigate the contribution of the addition of hydrated lime to the permeability of the prepared concrete in the permeability test and also its contribution to the physical characteristics of the test specimens in the mechanical compression test. It was observed that the masses made with hydrated lime had a lower voids index, due to the evaporation of the water, influencing the permeability of the pulp, which contributes significantly to the permissiveness of aggressive agents.

Keywords: Lime, Concrete, Permeability.
\end{abstract}

\section{Introdução}

O surgimento do PVC ocorreu a partir da descoberta do monômetro cloreto de vinila (MVC) por Justus Von Liebig, um gás à temperatura em ponto de ebulição a $-13,8^{\circ} \mathrm{C}$. Segundo FERNADES (2016), no artigo "Origem do PVC e seu Processo de Transformação", em 1872 a princípio registrou-se a polimerização do MVC e obtenção do PVC. Para obter o PVC é necessário que o MVC fosse induzido pela luz para assim ser transformado em um produto sólido branco. Este produto foi diagnosticado sendo um isômero do monômetro e a propriedade desta substância coincide com a composição apresentada pelo PVC.
O MVC ao ser submetido a processo químico suas moléculas se ligam criando-se uma molécula gigante com milhares de monômeros denominada polímero que é o PVC, um pó que ao ser misturado com aditivos sendo eles: plastificantes, estabilizantes, pigmentos e ao ser transformado dá origem ao composto de PVC, Rodolfo Jr (1999).

Com o passar dos anos houve uma demanda de reaproveitamento de todo material que é descartado na construção civil. A resolução do CONAMA 307:2002 diz "Considerando que a disposição de resíduos da construção civil em locais inadequados contribui para a degradação da qualidade ambiental";

Segundo o artigo $3^{\circ}$ do CONAMA 307: 2002 o

Afiliação dos autores: † Graduando em Engenharia Civil pela Universidade de Vassouras, Vassouras/RJ

\$ Docente MSc. em Engenharia Civil pela Universidade de Vassouras, Vasouras/RJ.

*Email para correspondencia: gustavojcg@id.uff.br 
PVC é classificado na classe B que engloba materiais recicláveis como plástico, papelão, papel, vidros, madeiras e outros.

Questões sobre esse desenvolvimento consciente, qualitativo e sustentável levaram a buscar soluções para o reaproveitamento do PVC.

"Considerando que os resíduos da construção civil representam um significativo percentual dos resíduos sólidos produzidos nas áreas urbanas;" aonde a mesma surge com o mecanismo facilitador de incentivo de reaproveitamento e dá base legal às atitudes voltadas para essa ação.

Cabe dizer ainda que o mesmo será usado em formas de fibras, que junto com a areia, formará o agregado miúdo. Buscando um resultado satisfatório durante os testes de verificação à compressão e permeabilidade o concreto com o PVC veio se tornar um meio para buscar uma diminuição de extração de areia buscando minimizar a degradação do meio ambiente.

\section{Características do PVC}

As principais características do PVC são: materiais leves, de fácil manuseio e aplicação, resistentes a ação de fungos, bactérias, insetos e roedores, à maioria dos reagentes químicos, choques e às intempéries, bom isolante térmico, elétrico e acústico, sólido, impermeável e gases e líquidos, durável e sua vida útil é superior a 50 anos, não propaga chamas, versátil e ambientalmente correto, reciclável e reciclado e sua fabricação é de baixo consumo de energia.

\section{Durabilidade do concreto}

A duração e a aplicação funcional das estruturas de concreto sofrem variações ao longo do tempo, em virtude das influências com o ambiente onde estão inseridas. Levando em conta que o concreto concede ao aço um amparo físico e químico, ainda sim tal proteção não é garantira de uma longa durabilidade.

Segundo a NBR 6118:2014, as estruturas elaboradas de concreto armado, necessitam em seu projeto parâmetros que garantam sua longevidade, segurança, estabilidade e seu desempenho estrutural de serviço durante o período correlato à sua vida útil, sob as circunstâncias ambientais previamente verificadas e conforme prescrito em projeto. Assim, o conceito de durabilidade tem sido expandido na acepção de ser parte integrante dos estágios do projeto, realização e emprego das estruturas.

Segundo a NBR 6118:2014, "durabilidade consiste a capacidade de a estrutura de resistir às influências ambientais previstas e definidas em conjunto pelo autor do projeto estrutural e pelo contratante, no início dos trabalhos de elaboração do projeto.” E ainda segundo a mesma norma, "por vida útil de projeto, entende-se o período de tempo durante o qual se mantêm as características das estruturas de concreto, sem intervenções significativas, desde que atendidos os requisitos de uso e manutenção prescritos pelo projetista e pelo construtor, bem como de execução dos reparos necessários decorrentes de danos acidentais."

\section{Porosidade}

Os vários tipos de vazios formados na pasta de cimento hidratada contribuem para caracterização de suas propriedades. Esse volume total dos vazios é chamado de porosidade.

Ovolumedeporos obtidos dependeprincipalmente do fator água/cimento $(\mathrm{a} / \mathrm{c})$, conforme descrito na Tabela 1.

Tabela 1. Volume de poros em pastas de cimento.

\begin{tabular}{cc}
\hline \hline $\mathrm{A} / \mathrm{C}$ & VOLUME DE POROS (\%) \\
\hline 0,4 & 23,3 \\
0,5 & 34,5 \\
0,6 & 42,1 \\
0,8 & 53,4 \\
\hline \hline
\end{tabular}

De acordo com o código FIP-CEB (Comitê Euro-international du Béton) de 1989, os parâmetros de maior importância na caracterização dos poros do concreto com relação ao transporte de substância é a porosidade aberta e a distribuição dos diâmetros dos poros. O referido código caracteriza porosidade aberta como conjunto de poros interconectados por meio dos quais o transporte de líquidos ou gases e/ou a troca de substâncias dissolvidas é possível.

O código FIP-CEB de 1989 ainda classifica os poros de acordo com suas características e origem como: poros de ar aprisionado (decorrente dos processos de adensamento do concreto), poros de ar incorporado (obtidos quando do emprego de aditivos incorporadores de ar), poros capilares (oriundos da saída de água livre do concreto) e poros do gel (devido à água de gel).

Os macros poros geralmente são poros com dimensões superiores a $1000 \AA$, decorrentes de problemas de adensamento (ar aprisionado) e do uso de incorporadores de ar (ar incorporado). Os poros capilares são gerados pela evaporação da água livre do concreto e possuem dimensões que variam entre $100 \AA \AA$ e $1000 \AA ̊$ em função da relação água/cimento ou do grau de hidratação. Os poros do gel, por sua vez, apresentam dimensões inferiores a $100 \AA$ e dependem do grau de cristalização 
dos produtos da hidratação, especificamente, do C-S-H (KIHARA \& CENTURIONE, 2005).

Adicionalmente, a zona de transição (zona ao redor dos agregados com maior porosidade, onde cristais de grandes dimensões são formados) pode contribuir para aumentar a capacidade de transporte no interior do concreto, principalmente quando se aumenta a fração de agregados, o que pode facilitar a interconexão entre as diversas zonas de transição (MARTYS apud NEPOMUCENO, 2005).

Dentre os mecanismos de transporte no concreto, os principais são: permeabilidade, absorção capilar, difusão e migração iônica.

A permeabilidade é caracterizada como o fluxo de um fluido devido ao gradiente de pressão. Ela qualifica a facilidade com que um fluido, sob uma diferença de pressão, atravessa um sólido poroso. A permeabilidade do concreto está ligada à sua porosidade, logo é influenciada pelos fatores que alteram o volume e a conectividade dos poros do concreto. Portanto, adição de minerais, o grau de hidratação, o fator água/cimento, teor de agregados e o consumo de cimento são fatores que de forma direta, influenciam na permeabilidade do concreto.

A absorção capilar é caracterizada como o fluxo de um fluido devido ao gradiente de umidade, ou ainda, como o transporte de líquidos devido à tensão superficial atuante nos poros do concreto.

A intensidade das forças capilares está ligada as características do líquido (densidade, viscosidade, tensão superficial), das características do sólido poroso (raio e continuidade dos poros), da energia superficial e do conteúdo de umidade. Essas forças capilares surgem provenientes da tensão superficial do líquido que penetra nos poros, provocando a ascensão desse líquido nos poros.

Segundo Helene (1993), capilares com menores diâmetros são muito menos intercomunicáveis, o que resulta em menores alturas de sucção e menores volumes absorvidos. Desta forma, fatores que alteram a microestrutura do concreto também influenciam a sua absorção capilar.

A difusão é o processo de transporte de substâncias de um meio para o outro devido a uma diferença de concentração. Este mecanismo é um processo espontâneo de transporte de massa por efeito de gradiente de concentração. Pode ocorrer no meio líquido e no meio gasoso. Dessa forma, agentes agressivos que comprometem as armaduras do concreto podem penetrar na forma de íons e na forma gasosa, como por exemplo, íons cloreto, íons sulfato, gás carbônico e oxigênio.

\section{Cobrimento}

armadura, assegurar uma ação estrutural combinada entre o aço e concreto. A espessura do cobrimento da armadura é um fator determinante na movimentação dos agentes agressivos: quanto maior a espessura, maior o intervalo de tempo até que os agentes atinjam a armadura. Logo, a qualidade do concreto quanto à baixa penetrabilidade e a espessura do cobrimento atua em conjunto.

\section{Resistência}

Segundo Mehta \& Monteiro (1994), a resistência de um material é definida como a capacidade de este resistir à tensão sem ruptura. A ruptura é algumas vezes identificada com o aparecimento de fissuras. De qualquer modo, deve ser lembrado que, ao contrário da maioria dos materiais industriais, o concreto contém microfissuras antes mesmo de ser submetido a tensões externas. No concreto, portanto, a resistência é relacionada com a tensão requerida para causar a fratura e é sinônimo do grau de ruptura no qual a tensão aplicada alcança seu valor máximo.

Nos sólidos, a porosidade e a resistência apresentam uma relação fundamental inversa. Logo, em um material com fases diversas como o concreto, um fator limitante da resistência está diretamente ligado à porosidade de cada componente ou fase.

Fatores como o adensamento, condição de cura, dimensões, mineralogia do agregado, aditivos, geometria e condições de umidade do corpo-de-prova e tipo de tensão exercem um efeito importante sobre a resistência, embora o fator a/c seja o mais importante para determinação da porosidade e consequentemente da resistência do concreto.

Em termos estruturais, o concreto caracterizase pela alta resistência à compressão, entretanto sua resistência à tração é baixa.

De acordo com Mehta \& Monteiro (1994), quanto à resistência à compressão em 28 dias, o concreto se divide em três categorias: Concreto de baixa resistência: resistência à compressão menor que $20 \mathrm{Mpa}$; concreto de moderada resistência: resistência à compressão de 20 a $40 \mathrm{Mpa}$; concreto de alta resistência: resistência à compressão superior a $40 \mathrm{Mpa}$.

Dentre as características do concreto, a resistência à compressão é a mais conhecida e estudada. Pode-se concluir que essa característica está diretamente ligada à natureza dos hidratos formados e do grau com que estes ocupam os espaços disponíveis, ou seja, os poros capilares. Assim, todos os fatores que influenciam na porosidade do concreto estão diretamente ligados ao aumento da resistência (fator a/c, composição do cimento, etc).

O objetivo do cobrimento é além de proteger a 


\section{Projeto experimental}

No afã de promover as ideologias sustentáveis nesse projeto, propõe-se o reuso do PVC. Primeiramente o PVC é triturado ao ponto de obter fibras para que juntamente com a areia, componham um novo tipo de agregado miúdo.

Com o objetivo de prever a capacidade de resistência mecânica à compressão e permeabilidade por absorção de água por imersão. Através de pesquisa, a resistência do concreto escolhida para elaboração dos corpos de prova foi de $40 \mathrm{Mpa}$. Foram feitos três traços, segundo a tabela de traços elaborados de Caldas Branco (1974), conforme a tabela 2.

O uso de brita (agregado graúdo) foi dispensado uma vez que a utilização das mesmas no concreto não propicia uma uniformidade da difusão de soluções, podendo acarretar descontinuidades, devido a acúmulos

\begin{tabular}{|c|c|c|c|c|}
\hline & $\begin{array}{c}\text { Areia } \\
(\%)\end{array}$ & $\begin{array}{c}\text { PVC Triturado } \\
(\%)\end{array}$ & $\begin{array}{c}\text { Cimento } \\
(\%)\end{array}$ & $\begin{array}{c}\text { Água } \\
(\%)\end{array}$ \\
\hline $1^{\circ}$ Traço & $2 \mathrm{~kg}(100 \%)$ & $0 \mathrm{mg}(0 \%)$ & $1 \mathrm{~kg}(100 \%)$ & $400 \mathrm{ml}(0,4 \%)$ \\
\hline $2^{\circ}$ Traço & $2 \mathrm{~kg}(100 \%)$ & $0 \mathrm{mg}(0 \%)$ & $1 \mathrm{~kg}(100 \%)$ & $500 \mathrm{ml}(0,5 \%)$ \\
\hline $3^{\circ}$ Traço & $2 \mathrm{~kg}(100 \%)$ & $0 \mathrm{mg}(0 \%)$ & $1 \mathrm{~kg}(100 \%)$ & $600 \mathrm{ml}(0,6 \%)$ \\
\hline $1^{\circ}$ Traço & $1.8 \mathrm{~kg}(90 \%)$ & $200 \mathrm{mg}(10 \%)$ & $1 \mathrm{~kg}(100 \%)$ & $400 \mathrm{ml}(0,4 \%)$ \\
\hline $2^{\circ}$ Traço & $1.8 \mathrm{~kg}(90 \%)$ & $200 \mathrm{mg}(10 \%)$ & $1 \mathrm{~kg}(100 \%)$ & $500 \mathrm{ml}(0,5 \%)$ \\
\hline $3^{\circ}$ Traço & $1.8 \mathrm{~kg}(90 \%)$ & $200 \mathrm{mg}(10 \%)$ & $1 \mathrm{~kg}(100 \%)$ & $600 \mathrm{ml}(0,6 \%)$ \\
\hline $1^{\circ}$ Traço & $1.6 \mathrm{~kg}(80 \%)$ & $400 \mathrm{mg}(20 \%)$ & $1 \mathrm{~kg}(100 \%)$ & $400 \mathrm{ml}(0,4 \%)$ \\
\hline $2^{\circ}$ Traço & $1.6 \mathrm{~kg}(80 \%)$ & $400 \mathrm{mg}(20 \%)$ & $1 \mathrm{~kg}(100 \%)$ & $500 \mathrm{ml}(0,5 \%)$ \\
\hline $3^{\circ}$ Traço & $1.6 \mathrm{~kg}(80 \%)$ & $400 \mathrm{mg}(20 \%)$ & $1 \mathrm{~kg}(100 \%)$ & $600 \mathrm{ml}(0,6 \%)$ \\
\hline
\end{tabular}

Fonte: Próprios autores.

de solução em diferentes regiões da estrutura, provocadas pelas irregularidades dos agregados graúdos, levando a um estado de diferente situação no mesmo corpo-deprova. Além disso, dispensar o uso de britas proporciona a confecção de corpos de provas menores.

\section{Confecção dos corpos de prova}

Os corpos de provas foram confeccionados com cimento CPIII-RS, areia lavada, água e PVC triturado. 
Os materiais e equipamentos usados foram: Grosa, colher de pedreiro, balde, balança de precisão, vibrador eletrônico, peneira de $1,18 \mathrm{~mm}$, formas de isopor, bandeja para mistura das massas,

Bureta, peneira de laboratório e formas para confecção de corpos de prova cilíndricos.

\section{Confecção de corpos de prova para ensaio de resistência mecânica à compressão}

Com a peneira de malha $1,18 \mathrm{~mm}$, o primeiro procedimento a ser realizado foi peneiração da areia com o objetivo de se obter a granulometria padrão. Posteriormente, com a balança de precisão, foi realizado a pesagem dos materiais, cimento, areia e PVC triturado. Para cada traço foram estipulados valores diferentes da relação água/cimento $(\mathrm{a} / \mathrm{c})$, visto que este índice implica nos níveis de porosidade do concreto, ou seja, para confecção da massa de concreto de cada traço haverá três amostras diferentes (fatores de a/c de 0,4, $0,5$ e 0,6$)$, considerados respectivamente valores de baixo, médio e alto teor de água. Após a preparação da massa do concreto, o adensamento do concreto é feito no vibrador mecânico elétrico e adensados nas formas metálicas cilíndricas com $10 \mathrm{~cm}$ de diâmetro e $20 \mathrm{~cm}$ de altura, conforme indica a figura 1 .

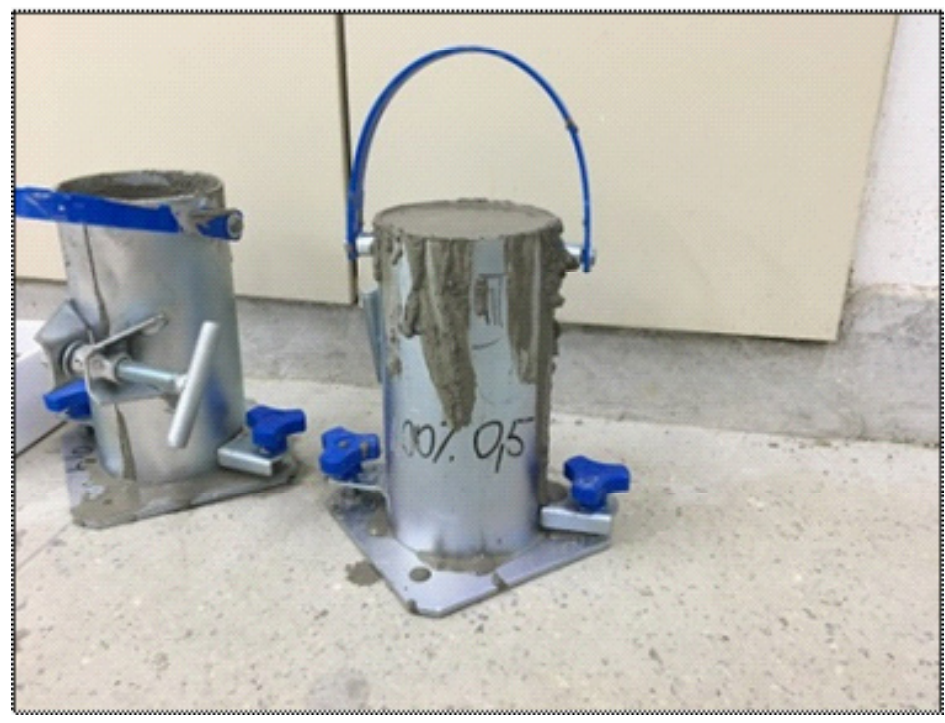

Figura 1. Corpos de prova cilíndricos (Fonte: Os autores).

Confeç̧ão de corpos de prova para ensaio de avaliação da permeabilidade or absorção de água por imersão

A confecção dos corpos de prova para este ensaio seguiu as proporções de traços e condições do ensaio anterior, variando apenas a moldagem dos corpos de prova onde para este, foram utilizadas formas prismáticas $10 \mathrm{~cm}$ de largura, 13 de comprimento e 6 $\mathrm{cm}$ de altura, conforme mostra a figura 2.

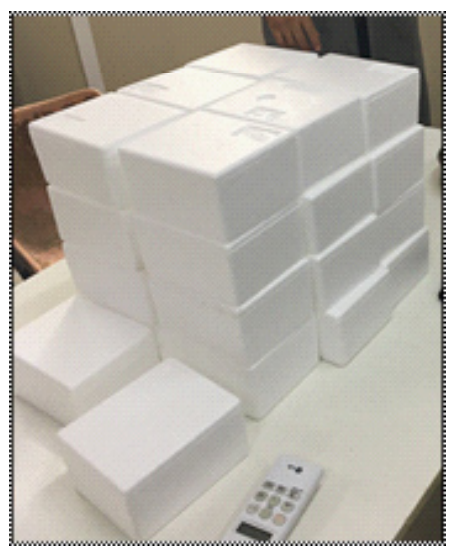




\section{Ensaio de resistência mecânica à compressão}

Para o ensaio de resistência mecânica à compressão, os corpos de prova seguiram os itens padronizados na NBR 5739:2007. Ao atingir o seu tempo de cura (28 dias), os corpos de prova foram lixados para uniformizar as superfícies irregulares. Segundo a NBR 5739:2007 "O corpo-de-prova cilíndrico deve ser posicionado de modo que, quando estiver centrado, seu eixo coincida com o da máquina, fazendo com que a resultante das forças passe pelo centro." (NBR 5739:2007). A calibragem do aparelho (figura 3 ) foi de $0,45 \mathrm{Mpa} / \mathrm{s}$.

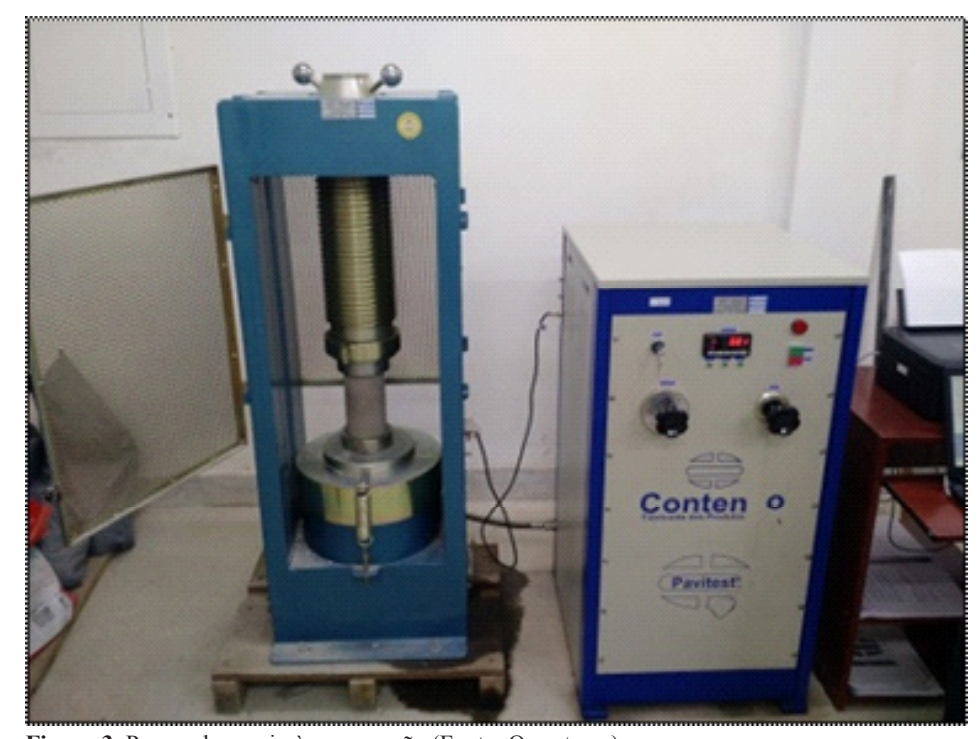

Figura 3. Prensa de ensaio à compressão (Fonte: Os autores).

Ensaio de avaliação da permeabilidade por absorção de água por imersão

Este ensaio seguiu os parâmetros preconizados nas NBR 9778:1987 e NBR 9779:1995.

Previamente a imersão dos corpos de prova no tanque, os mesmos foram lixado afim de que suas superfícies se tornassem uniformes, garantindo assim igualdade de absorção em todas as faces, conforme indica a figura 4.

Os corpos de prova foram imersos em água, até permanecessem completamente submersos em um tanque para banho em frascos de Le Chatelier, com sistema de aquecimento, onde a temperatura foi fixada em $45^{\circ}$, com o objetivo de acelerar o processo de absorção.
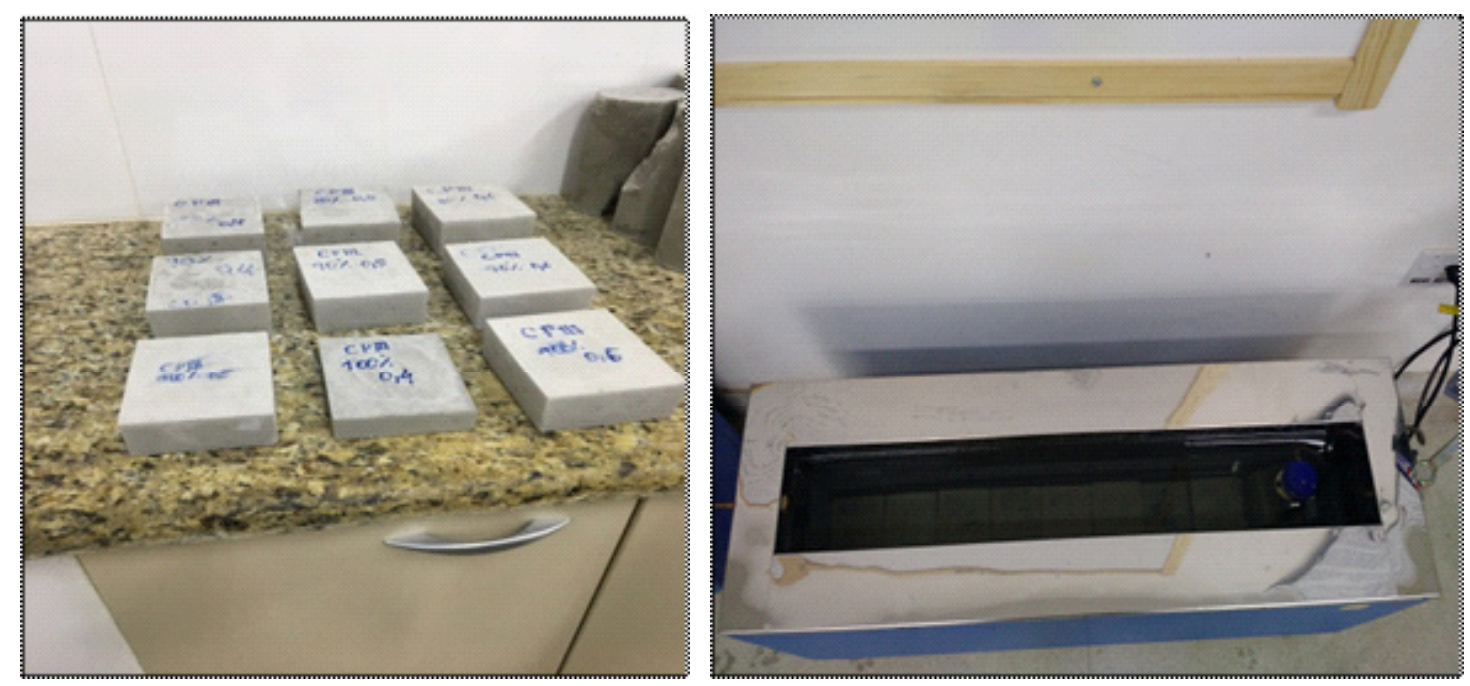

Figura 4. Corpo de prova prismático imersos no Tanque para banho em frascos de Le Chatelier com sistema de aquecimento. (Fonte: Os autores). 


\section{Resultados}

A tabela 3 mostra os resultados do ensaio a compressão onde é possível identificar que o aumento da relação água/cimento diminui a resistência segundo a Lei de Abrams, uma vez que a água ocupa espaços na pasta não endurecida que posteriormente ao evaporar cria espaços vazios que interferem na resistência e na permeabilidade do concreto já curado. Além disso, observa-se que o aumento do teor de PVC decresce o valor da resistência.
No ensaio de permeabilidade, segundo a tabela 4, observa-se que o uso do PVC aumenta o peso seco das amostras, porém após o tempo de imersão considerado, não houve diferença significativa de permeabilidade entre o concreto sem PVC e as amostras elaboradas com o resíduo de PVC.

\section{Conclusão}

Diante ao estudo apresentado, conclui-se a viabilidade do uso do PVC como substituição parcial do

Tabela 3. Resultados do ensaio à compressão no concreto.

\begin{tabular}{|c|c|c|c|c|}
\hline \multicolumn{2}{|c|}{$\begin{array}{l}\text { Resultados do } \\
\text { ensaio à } \\
\text { compressão }\end{array}$} & \multirow{2}{*}{$\begin{array}{c}\begin{array}{c}\text { Proporção de } \\
\text { Água }\end{array} \\
0,4 \%\end{array}$} & \multirow{2}{*}{$\begin{array}{c}\text { Tensão de } \\
\text { ruptura }\end{array}$} & \multirow{2}{*}{$\begin{array}{l}\text { Resistência } \\
43,33 \mathrm{Mpa}\end{array}$} \\
\hline CP $100 \%$ & $1^{\circ}$ traço & & & \\
\hline & $2^{\circ}$ traço & $0,5 \%$ & $50,6 \mathrm{Mpa}$ & 40,49 Мра \\
\hline & $3^{\circ}$ traço & $0,6 \%$ & $40,6 \mathrm{Mpa}$ & $33,54 \mathrm{Mpa}$ \\
\hline \multirow[t]{3}{*}{ СР 90\% } & $1^{\circ}$ traço & $0,4 \%$ & 51,9 Mpa & 41,53 Mpa \\
\hline & $2^{\circ}$ traço & $0,5 \%$ & $48,0 \mathrm{Mpa}$ & $38,43 \mathrm{Mpa}$ \\
\hline & $3^{\circ}$ traço & $0,6 \%$ & 36,9 Mpa & 29,5 Mpa \\
\hline \multirow[t]{3}{*}{ CP $80 \%$} & $1^{\circ}$ traço & $0,4 \%$ & 41,7 Mpa & $20,20 \mathrm{Mpa}$ \\
\hline & $2^{\circ}$ traço & $0,5 \%$ & 40,4 Mpa & $32,48 \mathrm{Mpa}$ \\
\hline & $3^{\circ}$ traço & $0,6 \%$ & $36,9 \mathrm{Mpa}$ & $30,47 \mathrm{Mpa}$ \\
\hline
\end{tabular}

Fonte: Próprios autores.

Tabela 4. Resultados do ensaio de permeabilidade.

\begin{tabular}{|c|c|c|c|c|c|c|}
\hline \multicolumn{2}{|c|}{$\begin{array}{l}\text { Ensaio de } \\
\text { Permeabilidade }\end{array}$} & \multirow{2}{*}{$\begin{array}{l}\text { Seco } \\
1,6076\end{array}$} & \multirow{2}{*}{$\begin{array}{l}\text { 3hrs } \\
1,6515\end{array}$} & \multirow{2}{*}{$\begin{array}{l}\text { 24hrs } \\
1,6656\end{array}$} & \multirow{2}{*}{$\begin{array}{l}\text { 48hrs } \\
1,6665\end{array}$} & \multirow{2}{*}{$\begin{array}{l}72 \mathrm{hrs} \\
1,6660\end{array}$} \\
\hline & $0,4 \%$ & & & & & \\
\hline \multirow[t]{3}{*}{ CP $100 \%$} & $0,5 \%$ & 2,6178 & 2,6667 & 2,6799 & 2,6821 & 2,6817 \\
\hline & $0,6 \%$ & 2,7847 & 3,0481 & 2,8548 & 2,8579 & 2,8574 \\
\hline & $0,4 \%$ & 3,0790 & 2,8409 & 3,1323 & 3,0896 & 3,1526 \\
\hline \multirow[t]{3}{*}{ CP $90 \%$} & $0,5 \%$ & 3,0236 & 3,0741 & 3,0871 & 3,0896 & 3,0644 \\
\hline & $0,6 \%$ & 2,9798 & 3,0481 & 3,0622 & 3,0651 & 3,0644 \\
\hline & $0,4 \%$ & 3,3424 & 3,4035 & 3,4269 & 3,4277 & 3,4269 \\
\hline \multirow[t]{2}{*}{ CP $80 \%$} & $0,5 \%$ & 3,5005 & 3,5830 & 3,6213 & 3,6240 & 3,6233 \\
\hline & $0,6 \%$ & 3,2609 & 3,3632 & 3,3986 & 3,4015 & 3,4011 \\
\hline
\end{tabular}


agregado miúdo, uma vez que os ensaios demonstraram resultados satisfatórios.

Segundo IBAMA, o PVC leva de 200 a 600 anos para se decompuser na natureza, diante disso o seu aproveitamento como resíduo, gera impacto ambiental positivo uma vez que evita o seu descarte no meio ambiente.

Necessita de estudo mais aprofundado para se chegar em uma zona ótima, em que se consiga estipular valores precisos da quantidade equivalente que pode ser alternada ou a inclusão de algum aditivo que melhore as condições física e químicas das massas elaboradas com PVC.

\section{Referências bibliográficas}

Associação Brasileira De Normas Técnicas. NBR 9778: Argamassa e concreto endurecido - Determinação da absorção de água por imersão Índice de vazios e massa específica, 1987. Rio de Janeiro.

Associação Brasileira De Normas Técnicas. NBR 9779: Argamassa e concreto endurecido - Determinação da absorção de água por capilaridade. 1995. Rio de Janeiro.

Associação Brasileira De Normas Técnicas. NBR 5739: Ensaio de compressão de corpo-de prova cilíndrica, revisada em 2007. Rio de Janeiro.

Associação Brasileira De Normas Técnicas. NBR 6118: Projeto de execução de obras de concreto armado, revisada em 2014. São Paulo.

Resolução Conama No 307. 2002 Publicada no DOU no 136, de 17 de julho de 2002, Seção 1, páginas 95-96.

Abílio De Azevedo Caldas Branco, 2016. Tabela de Traços Eng. Caldas Branco, 1974.

Fernandes, Silvio Soares; Diacenco, Adriana Amaro. Origem do PVC e seu processo de transformação. Centro Universitário de Itajubá - FEPI, Avenida Dr. Antônio Braga Filho, 687 Varginha - Itajubá-MG.

Ihara, Y.; Centurione. S. L. 2005. O cimento Portland. In: Concreto - Ensino, Pesquisa e Realizações. Editor, Geraldo C. Isaia. $1^{\circ}$ Edição, v. 01. Editora Ibracon. São Paulo.

Helene, Paulo R. L. 1993. Contribuição ao estudo da corrosão em armaduras de concreto armado. São Paulo, Tese (Livre docência). Escola Politécnica, Universidade de São Paulo.

Mehta, P. K.; Monteiro, P. J. M., 1994. Concreto: Estrutura, Propriedades, Materiais, São Paulo, Pini.

Nepomuceno, A.A. 2005. Mecanismos de transporte de fluidos no concreto. In. Concreto: Ensino, Pesquisa e Realizações. Ed. G.C. Isaia. São Paulo: IBRACON, v.2. p. 793-827. 